\title{
Community-Based Interventions and Behaviors of HIV+ Persons in Congo-Kinshasa
}

\author{
Max Ebengho-Bokelo ${ }^{1}$ \& Jeremy Super-Eloko ${ }^{2}$ \\ ${ }^{1}$ Department of Public Health, Walden University, United States of America \\ ${ }^{2}$ Congolese Medical Doctor, Congo-Kinshasa (DRC-Government MD) \\ Correspondence: Max Ebengho-Bokelo, 4901 East I. Street, Tacoma, WA 98404, United States of America.
}

Received: August 9, 2021

Accepted: September 4, 2021

Online Published: September 9, 2021

doi:10.5539/mas.v15n5p27

URL: https://doi.org/10.5539/mas.v15n5p27

\begin{abstract}
Introduction: Sub-Saharan African communities bear the highest burden of HIV/AIDS in the world. Because of identifiable cultural links and local beliefs, people are more likely to engage in sexual mores that could negatively impact their life. Starting in early 2000, Congolese HIV+ patients have undergone a variety of medico-social inputs designed to decrease risky behaviors among people in the program and their family members.
\end{abstract}

Goals: This inquiry aimed to understand how PLWHs assess the influence of community-based incentives within their society, as primarily conceived to improve daily behaviors of each person living with HIV (PLWH), and a few selected family members with unknown HIV-serostatus.

Methods: From December 2020 to March 2021, a cross-sectional study was engaged to gather qualitative-driven information from nine in-depth interviews, three focus groups, and two key-informant interviews. Changes were self-assessed through data gotten from 2004-2014 in sexual cleansing, levirate and sororate marriage, Kintwidi phenomenon, stigma and discrimination, sexual gender-based violence (SGBV) and female genital mutilation (FGM), unprotected receptive vaginal or anal intercourse, and behavioral rejection of condoms throughout a decade of Congolese Community-based Interventions (CBIs) implemented from 2004. Grounded on the socioecological model (SEM), this ethnographic study was based on the meaning of the influence of CBIs on cultural behaviors among PLWHs for HIV/AIDS prevention purposes.

Results: Data from Kinshasa and Bandundu were coded and analyzed through NVivo R1 and Excel, showing significant negative sentiments for all eight key-cultural components in PLWHs.

Conclusion: Out of the holistic approach employed to tackle HIV/AIDS in communities, the comprehensive strategy enabled for social change in Congo-Kinshasa brought specific impactful insights in terms of behavior according to interviewed PLWHs. Findings could be used to inform further preventive activities to alleviate any community HIV burden in sub-Saharan Africa.

Keywords: Community-based interventions, behavior, socioecological model, HIV and people living with HIV

\section{Background}

This literature review surveys articles addressing behavioral issues of HIV+ individuals among different communities, especially those using community-based interventions (CBIs) as one of the principal approaches for HIV epidemic control in a specific cultural context. The scope of the study was based on selected articles and publications designed to frame the understanding of eight random key concepts: (1) levirate marriage, (2) sororate marriage, (3) Kintwidi phenomenon, (4) sexual gender-based violence (SGBV) and female genital mutilation (FGM), (5) sexual cleansing, (6) poor condom usage for cultural reasons, (7) unprotected receptive vaginal or anal intercourse, and (8) discrimination and stigma. For instance, Hile et al. (2018) employed in-depth individual and group interviews from 42 participants to identify factors that could be incorporated to promote positive HIV-related behavior and self-management in New York City. Further, Zhang et al. (2018) suggested new directions for African American men who have sex with men (MSM) as elements to inform HIV programs and positive behavioral intervention to reduce community risks of HIV transmission.

Focusing on the Latino population, Martinez et al. (2016) explored local data from male couples to adapt evidence-based behavioral HIV prevention interventions by performing a combination approach. Conroy et al. (2018) wrote about creating an overlap between integrating sociocultural approaches and empowering women to 
take the dyadic environment and men's perspectives. Two years before, Mataboge et al. (2016) proposed how teaching community members in coaching teenagers could support each other in order to bridge strategies and increase HIV/AIDS prevention in South Africa. In 2015, Wekesa and Coast experimented with reproductive health services, including HIV prevention and the needs of PLWHs regarding contraceptives in Nairobi, Kenya. However, Pretorius et al. (2016) did not find significant differences in HIV-Stigma reduction programs targeting PLWHs and their family members in South African between rural and urban areas, but the intervention showed positive results.

Meanwhile, some mixed studies have been also reviewed. For example, Gorofalo et al. (2018) performed a project life-skills randomized clinical trial targeting behavioral intervention among young transgender women who showed a greater reduction in condomless sex acts for one year. But two years before, Collins and Sapiano (2016) wrote about the diffusion of effective behavioral interventions as an opportunity for other large evidence-based projects. Likewise, Ahmed et al. (2016) outlined PLWH patients' beliefs and their behavior when facing complementary and alternative medicine. The authors suggested community interventions towards medication adherence in younger adults with higher income and the syndrome of depression. Mandumbu and Mariga (2017) provided non-material intervention with strategies to improve agriculture for PLWHs and elderly farmers in security in sub-Sahara Africa.

A number of scholars have approached this topic from different angles and with different focuses. Sun et al. (2018) focused on a socio-ecological perspective using intersectionality theory in HIV care to reach the incidence reduction through community-based approaches. Mustafa (2018) published an article on U.S. Black men living with HIV regarding prevention among special communities such as fishermen, teenagers, and inmates. Meanwhile, Zhou et al. (2018) illustrated more attention is needed in different Chinese communities. Indeed, different places identified as high, medium, and low levels provided different levels of condom use and HIV/STD prevalence in heterosexual transmission mode. Similarly, Wang et al. (2018) investigated targeted risk behaviors regarding HIV/AIDS among female sex workers in Yunnan border, China. In 2018, Luo et al. compared behavior changes among female sex workers in Asia and newly diagnosed HIV-positive men having sex with men around the same location.

The same year, Ousley et al. (2018) found that HIV fishermen in Myanmar have a higher risk of hepatitis C co-infection because they disproportionally engage in drug injection use and higher risk of transactional sex than other patients. Screening people's attitudes, Sharma et al. (2018) outlined the high-risk behavior regarding drug users and co-infection with hepatitis $\mathrm{C}$ virus risks among inmates. When describing the SEM, Glanz et al. (2015) highlighted five core principles impacting health behavior stating: (1) the multiplicity of levels of influence, (2) the significance of determinants, (3) the interaction of influences of behaviors across levels, (4) the specificity of SEM on a particular behavior, and (5) the fact that multilevel interventions should be most effective in shaping behaviors as desired. On a different point, Leddy et al. (2018) showed that food insecurity was associated with poor health among PLWHs in the United States of America. In summary, more than 75 articles focusing on CBIs have been reviewed, including those written by Gilbert et al. (2015), Bhatta et al. (2018), Yang et al. (2018), Merlin et al. (2018), Burman and Aphane (2017), Mahvu et al. (2017), Belmar and Stuardo (2017), and Poku and Bonnel (2016).

Tackling gender difference in the North-Central Nigeria, Orisaremi (2016) explored sexual health seeking behavior, gender, and the spreading of HIV/AIDS. The author found certain negative effects of gender inequality in women's sexual health seeking behavior (Orisaremi, 2016). Otherwise, according to the U.S. President's Emergency Plan for AIDS Relief (PEPFAR, 2017), Congolese HIV+ patients have received bi- and multilateral assistance from different health partners for HIV diagnosis, treatment, and community interventions. In 2019, PEPFAR underwent multiple difficulties in tracking progress when assessing the impact of a project and the threshold gap from making a significant improvement toward a needed change. However, despite post-2000 funding activities to control HIV via the Global Funds, World Bank, World Health Organization (WHO), UNICEF, Department for International Development (DFID), and local Congolese partners, nobody knows if the provided CBIs were significantly impactful for PLWHs themselves and their family members while facing their own cultural barriers.

Grounded on the SEM with all its 5 components, this study is an opportunity to motivate scientific attention to consider the missing link between some highly country-funded programs as in Congo-Kinshasa from 2004 to 2014, and the lack of evaluated results for further improvements in similar or parallel programmatic activities. For Shi and Johnson (2013), cultural behaviors as barriers could be mistakenly ignored, but people need to know how, when, where, and with whom to partner for specific, attainable, measurable, relevant, and time-bound results. The idea is to set up key ingredients helping in building in DR Congo and elsewhere a successful strategy for HIV epidemic control (PEPFAR, 2019). And the major link between all the articles above and this paperwork is the 
established relationship between HIV, people's behavior, and community-based interventions. This qualitative ethnographic study finally occurred in two cities of DR Congo in 2020, instead of three as previously planned. Eight random cultural key-components have been chosen to understand how PLWHs assess the influence of CBIs in the behavior of PLWHs. Three main research questions guided this 10-year cross-sectional ethnographic study among HIV+ persons living in DRC and their family members:

1) In what ways has participation in CBIs impacted sexual behaviors among Congolese PLWHs and the community in general?

2) What is the meaning of CBIs for family members?

3) What are the detailed sociocultural behaviors impacted at the end of different CBI projects?

\section{Literature Review}

According to the WHO (2017), Africa is the most HIV-infected region in the world, bearing almost $70 \%$ of all HIV-affected individuals. Meanwhile, Rosenberg et al. (2017) suggested that older PLWHs in rural hyperendemic communities of South Africa had sexual behaviors consistent with high HIV transmission risk status. Studying risky sexual behaviors among in-school adolescents and HIV risk perception in Ghana, Afriyie and Essilfrie (2019) proposed that adolescents did not perceive themselves to be at risk of HIV infection despite their risky behavior. Whittle et al. (2019) suspected that food insecurity may be associated with a range of poor mental health results among women at risk of HIV in the United States of America. MacLean and Wetherall (2021) found a bidirectional relationship between mental depression and stigma. They figured out that female and young PLWHs are more likely to develop adverse effect to stigma (McLean \& Wetherall, 2021). This statement highlights the particular interest of organizing social interventions within communities.

WHO (2017) reported that more than 25.7 million people were living with HIV in Africa, out of a total 36.9 million globally. However, in a systematic review involving four databases, Fearon et al. (2019) were not able to present conclusive evidence regarding the role of peers in adolescent sexual behavior among vulnerable sub-Saharan Africans. When studying risk and resilience regarding the nature of HIV among indigenous people in Ecuador, Dao et al. (2019) found that the identified risk factors of HIV/AIDS were interconnected within a mosaic of syndemic relationships. They demonstrated that, among indigenous communities, the mutually reinforcing individuals' risk level of sexual behavior, violence, and substance abuse increased the risk of HIV (Dao et al., 2019). However, I found nothing in my review of the literature regarding a likelihood in a change of attitude obtained from the influence of any CBI project in Congolese sociocultural behaviors.

The purpose of this ethnographic research is to assess whether Congolese PLWHs have undergone any changes in sociocultural behaviors as a consequence of the CBIs previously planned to alleviate the burden of HIV/AIDS in different communities. For instance, Techasrivichien et al. (2016) demonstrated that Thai sexual norms were drastically changing with their lifestyle and practices, creating a significant gap between the older generation and young Thai people. Besides the antiretroviral treatment approach, the U.S. President's Emergency Plan for AIDS Relief (PEPFAR, 2017) tracked the Congolese community-based response addressing the HIV/AIDS crisis through home visits, then outreach and VCT programs within 26 provinces. Unfortunately, nobody has explained whether, during the implementation process, patterns of Congolese sexual behaviors and gender-based sociocultural attitudes have been modified throughout CBIs while addressing HIV/AIDS.

Listing a selected group of gender-based behaviors of interest, this inquiry will be randomly focused on (1) HIV/AIDS stigma and discrimination, (2) levirate marriage (i.e., the custom decreeing that a woman marry a widowed brother-in-law as a matrimonial cousin), (3) sororate marriage (i.e., the custom whereby a man marries a dead wife's sister; Malungu, 2001; Westreich, 2004), (4) unprotected receptive vaginal or anal intercourse (WHO, 2018), (5) rejection of condom use for cultural reasons, (6) mores culturally breaking incest among an uncle and his own nieces identified as the "Kintwidi phenomenon" (Shan \& Cui, 2018), (7) SGBV and FGM (Fawole, 2018; WHO, 2019), and (8) sexual cleansing (Vera et al., 2018) or a Mongo tribe's mores spiritually setting free a widow through unprotected receptive sex with another widow or a mentally disabled person. How did Congolese PLWHs under CBI's understanding of high-risk sexual behavior change follow the implementation of different ongoing community projects?

To better understand the relevance of the problem, Omori and Abu-Raddad (2016) strived to depict the missing links in sub-Saharan Africa HIV prevalence and the population's sexual behaviors through 25 countries using the Demographic Health Survey data. That socioecological study revealed that population behavior was not predictive of HIV infection (Omori \& Abu-Rabbad, 2016). Paradoxically, data from the Kaiser Family Foundation (2017) suggested that DR Congo is the only country in the central African region holding less than 1\% 
of HIV prevalence among individuals aged 15 to 49 years. According to the United Nations' AIDS organization (UNAIDS, 2018), all the neighboring countries have a higher incidence of HIV/AIDS than what DR Congo bears, including $11.5 \%$ of prevalence for Zambia, $7.9 \%$ for Uganda, $3.1 \%$ in Congo-Brazzaville, $2.7 \%$ in Rwanda, and $1.9 \%$ in Angola. Could sociocultural behaviors explain the low HIV serostatus in DR Congo?

Conroy et al. (2019) established a relationship between food insecurity and sexual violence. For instance, an observational study from UNAIDS (2017) reported that $49.2 \%$ of Congolese would never buy vegetables from shopkeepers living with HIV. That isolated fact may be understood as a sign of stigma and discrimination against PLWHs. Meanwhile, CBIs have been applied since 2004, and for CDC (2017), the World Bank (2018) suggested that $0.8 \%$ of Congolese adults between the ages of 15 and 49 are HIV infected out of 78,736,153 inhabitants. Besides CBIs, antiretroviral treatments (ART) administration is employed for 122,268 people under treatment since 2015 , because there are more than 19,000 people at risk of death in the country (CDC, 2016). For this study, I used in-depth interviews, key-informant person interviews, and focus groups to collect and compare qualitative information from living HIV+ people and their family members who have been in the program in order to understand the behavioral impact of the CBIs in at least three of the following provinces of DR Congo: Kinshasa Haut-Katanga, Bandundu, Kongo Central, Kasai, and Equateur.

\section{Materials and Methods}

\subsection{Setting and Study Design}

This is a cross-sectional study collecting 10 years of information from 2004 to 2014 using a community HIV-centered approach. Data were collected in Kinshasa with ACS AMO Congo, and in Bandundu-city with the Health District. ACS AMO Congo is a nonprofit organization addressing HIV in Kinshasa, and the health center office of the health district was designed to organize data collection from the General Referral Hospital in Bandundu-city. In fact, Mbandaka was supposed to be the third data collection site. But it was finally excluded by the Walden IRB because I have a particular relationship with each PLWH in that site where I worked for 18 years. PLWHs in Mbandaka are potentially more likely to provide positive answer to any factual questions while seeking for objective responses.

\subsection{Approach}

In this article, it is planned the use of the SEM to understand a possible connection between CBIs and behaviors of PLWHs. Behavioral change is the phenomenon under study that leads all observations from the initial behavior status of each respondent. However, as previously stated, when using a self-report approach in this context, participants provide their own opinion for research purposes. Because all of the participants in the study are PLWH, this could potentially be the starting point of the HIV spread within and outside the community, if they do not behave positively where they live. Behaving positively explained as a potential cultural behavior leading to prevent a person from contracting HIV. According to Davis et al. (2015), theories of behavior have linearity that explains why behavior may occur after considering a number of predictors associated with one another having a probable impact on a particular attitude. SEM is believed to provide comprehensive frameworks to understand the variety and interacting determinants of health within and outside of social layers (Salazar et al., 2015). To make a connection with practice, Hickson et al. (2015) suggested a Minority HIV/AIDS Research Initiative (MARI) to understand the rationale of sexual behaviors and HIV/STI among 800 African American MSM in the southeastern United States. The traditional HIV environmental riskscape has shown empirical evidence that HIV transmission risk among a targeted population of African American MSM is highly affected in the deep south (Hickson et al., 2015). As a tool for digging into people's traditions, ethnography was an interesting, well-suited tool to support this study, as cultural behaviors are involved when understanding individuals' thoughts regarding sociocultural mores among Congolese HIV+ persons.

\subsection{Study Participants}

Rudestam and Newton (2015) suggested that data gathered in qualitative studies are expressed in words, the reasoning is inductive and depending on the topic analyzed, the phenomenon of study could be naturally occurring or contextual. In fact, three important groups of people are targeted in this study: (1) eligible middle school education level (or above) HIV+ patients under CBI from 2004 to 2020 in three of 26 provinces of DR Congo, (2) adult family members of PLWHs who lived with them for at least 6 months under the CBI program, and (3) HIV negative people or unknown serostatus individuals who never been in any CBIs. The selection logic was done with no gender, no religion, and no social class discrimination, and all participants needed to provide proof of identification and be at least 18 years old on the starting day of data collection. Also, because I worked for 7 years with all PLWHs in Mbandaka, only two sample cities using CBIs with HIV treatment centers were selected to conduct the study and reduce bias risks: Bandundu, and Kinshasa. 
Involving a research assistant, the selection of participants in study groups was done according to the principle of voluntary participation. HIV-negative and unknown serostatus respondents of age 18 and older were selected in the comparison group, while HIV+ patients and family members of age 18 and plus were selected into the study group. Respondents were informed regarding their all benefits and the expectations of the study, then it was clearly stated that self-withdrawal from participation in this inquiry could happen any time and whenever the person feels free to leave the study. All the respondents were asked to stay in touch with the researcher after data collection, because of a possible return for follow-up interviews for clarifications.

Self-withdrawal of participants is one of the guiding principles of social studies (Salazar et al., 2015; Babbie, 2015). In fact, respondents were clearly explained that they are free to exit the study anytime they want in a simple procedure. Meanwhile, respondents prescheduled in this study for an interview could be revisited if any valid reason occurs while implementing data collection. For instance, a natural disaster occurring, an unexpected sickness, a hospitalization of a child, a war, or any other acceptable reason that could prevent a participant from attending on-time data collection site. Follow-up procedures was planned to occur in physically meeting the person at home, of after the individual decided to reach out to the team. Missing a focus group will potentially not affect the study project until the sample size decreases below six (Babbie, 2015).

These qualitative data were planned to be remotely collected in late 2020 from DRC, after the Walden IRB approval, and under the guidance of the Congolese Ethics Association. Accordingly, the sampling method was purposive, since a qualitative researcher is more likely to deliberately seek knowledgeable respondents who can contribute significantly to the expected outcomes (Rudestam \& Newton, 2015). Because HIV is a sensitive matter, participant selection was based on confidentiality, using informed consent and voluntary participation for either PLWHs aged 18 and above under CBI project with at least middle school education level, or adult family members living with PLWHs for at least six months. Synchronically, groups of non-HIV people or unknown serostatus individuals composed a comparison group. Selected participants claimed to meet the criteria at their non-disclosure mode choice of communication, after the local committee board named selected participants in a confident signed-coded list containing only identification initials of elected respondents for the study. Mbandaka city being excluded to avoid bias since I worked with all PLWHs before, each site had two gender-based focus groups, six in-depth qualitative interviews, and six gender-based key informant persons.

\subsection{Data Collection}

Addressing the trustworthiness, Yang et al. (2016) performed a qualitative study collecting information on the validity of the culturally embedded risk factors for Cambodian husband-wife HIV transmission in Phnom Penh, Cambodia. The authors used 15 in-depth interviews with women becoming infected with HIV from their HIV+ husbands (Yang et al., 2016). Interviews were conducted in Khmer, and the trustworthiness of study outcomes was protected through peer debriefing, coding process to consensus, and maintaining an audit trail (Yang et al., 2016). That is why in order to increase data trustworthiness in this study and obtain the IRB approval, informed consent, minimal risks, anonymity, confidentiality, trustworthiness, voluntary participation, and guaranty of withdrawal every time while organizing the research were required (Babbie, 2015).

Qualitative validity referred to the scale measuring exactly what the tool is supposed to measure (Salazar et al., 2015). Multiple validity procedures were engaged to establish the credibility of this study, such as (1) triangulating different data sources instead of collecting information from one single site, (2) member checking approach by comparing obtained results from participants' information, (3) rich, thick description or detailed descriptions of the setting with site transportation possibility, (4) bias clarification from self-reporting with an attention on social desirability bias, inaccurate recall bias, selective recall bias, (5) discrepant information, (6) spending prolonged time in the field for data collection verification purpose, (7) using peer debriefing to improve the accuracy of the account, and (8) employing external auditor to review the entire project of the study (Creswell \& Creswell, 2018).

The reliability of this study was checked through documentation related to the procedures of using self-report to understand the effects of CBI among HIV+ persons in DRC. The database setup must reflect information collected from the respondents (Creswell \& Creswell, 2018). This will be done by (1) checking the transcripts, (2) removing drifts from code definitions, coordinating the communication among coders through regular documented meetings and sharing analyses, (4) cross-checking codes from other searchers (Creswell \& Creswell, 2018). Probable transferability or external validity will be assumed by providing enough contextual data related to CBIs and framing for outsiders to be fully able to contextualize the study (Salazar et al., 2015). Also, the dependability will be based on audit rails and the triangulation approach, according to the fact that this qualitative study has a pioneering inquiry collecting information regarding how respondents understand the effects of their own 
sociocultural facts (Creswell \& Creswell, 2018; Salazar, 2015). The counterpart to objectively observing cultural facts would define the confirmability of this qualitative study, checking if someone around provided similar results to an identical study (Ravitch \& carl, 2016). At the end of the data collection process, it would be imperative to make sure the conclusion reflects information as provided by the intra-and intercoder chain.

As stated above, 42 PLWHs remotely and physically responded to three different types of interviews from Congo-Kinshasa. Data were recorded from their voluntary participation to this qualitative study designed to understand if CBIs, as applied in DR Congo, have had an impact on the behaviors of Congolese PLWHs. Table 2 describes the details of the data collection.

Table 1. Data Collection Type, Location, and Respondents' Demographics

\begin{tabular}{llllllll}
\hline$\#$ & Activity & Respondents & City & Location & Age & Gender & Date \\
\hline 01 & Focus group & 12 & Kinshasa & AMO Congo & $27-50$ & $\mathrm{~F}$ & $12 / 27 / 20$ \\
02 & Focus group & 6 & Kinshasa & AMO Congo & $32-55$ & $\mathrm{M}$ & $12 / 27 / 20$ \\
03 & Focus group & 13 & Bandundu & BCZS-BDD & $30-55$ & $\mathrm{~F} / \mathrm{M}$ & $1 / 20 / 21$ \\
04 & Key-informant & 1 & Kinshasa & AMO Congo & 57 & $\mathrm{M}$ & $2 / 28 / 21$ \\
05 & Key-informant & 1 & Bandundu & Kingston, NY & 57 & $\mathrm{M}$ & $2 / 27 / 21$ \\
06 & In-depth interviews & 5 & Kinshasa & AMO Congo & $27-50$ & $4 \mathrm{~F} / 1 \mathrm{M}$ & $1 / 03 / 21$ \\
07 & In-depth interviews & 4 & Bandundu & BCZS-BDD & $30-55$ & $3 \mathrm{~F} / 1 \mathrm{M}$ & $1 / 21 \mathrm{~s}-22 / 21$ \\
\multicolumn{2}{l}{ Total } & 42 & 2 cities & 2 locations & Years & $26 \mathrm{~F} / 16 \mathrm{M}$ & $12 / 20-3 / 21$ \\
\hline
\end{tabular}

Based on those two chosen sites, three focus groups of eight to 14 people equally selected on gender basis resemblance occurred over one and half hours, with nine in-depth qualitative interviews of one hour each, and 60 minutes of two key informant persons through the two selected sites. Data were audiotaped (Zoom meeting), and depending on selected sites, focus groups took place either among PLWHs or identified family members in order to have at least $20 \%$ of their opinion as the outcome. This was the same for other data collection layers, and people who had never been in any program were also interviewed. The in-depth interviews were semi-structured and unstructured (Robin \& Robin, 2012). Semi-structured interviews were privileged, and the gap in the literature review regarding the influence of CBI programs applied on PLWHs in DR Congo and the difference in HIV seroprevalence with neighboring countries was emphasized as the rationale feeding this study. An existing local HIV+ patients' network was used to generate participants in each provincial coordination of the National HIV/AIDS Program known as Programme National de Lutte Contre le Sida (PNLS).

\section{Data Analysis}

Collecting data related to the influence of CBIs on behaviors of HIV+ persons under the program required the use of a computer-assisted qualitative data analysis software (CAQDAS). Fortunately, self-report is based upon what the individual knows and ultimately what has changed, so the coding process was used as the main way of getting qualitative data ready for analysis with CAQDAS (NVivo R1) (Rudestam \& Newton, 2017). Saldana (2016) warned researchers about one of the most frequent concerns that they usually feel overwhelmed by the wide array of coding methods to choose for data analysis. For instance, magnitude coding allowed a choice to a respondent between 3 = high, 2 = medium, $1=$ low, and $0=$ none (Saldana, 2016).

Table 2. Data Analysis Process

\begin{tabular}{|c|c|c|c|}
\hline $\begin{array}{l}\text { Recherche questions } \\
\text { versus data analysis }\end{array}$ & $\begin{array}{l}\text { RQ1. In what ways do participation in } \\
\text { CBIs has impacted sexual behaviors } \\
\text { among Congolese PLWH and the } \\
\text { community in general? }\end{array}$ & $\begin{array}{l}\text { RQ2. What is the meaning of } \\
\text { Community-based } \\
\text { Interventions for family } \\
\text { members? }\end{array}$ & $\begin{array}{l}\text { RQ3. What are the detailed } \\
\text { sociocultural behaviors } \\
\text { impacted at the end of the } \\
\text { projects? }\end{array}$ \\
\hline Connection of data & $\begin{array}{l}\text { Interview, focus group, key informa } \\
\text { transcripts }\end{array}$ & $\begin{array}{l}\text { Interview, focus group, key } \\
\text { informant transcripts }\end{array}$ & \\
\hline $\begin{array}{l}\text { Type and procedure of } \\
\text { coding }\end{array}$ & $\begin{array}{l}\text { Transcripts Microsoft Word, then Excel } \\
\text { using double cycle magnitude coding }\end{array}$ & $\begin{array}{l}\text { Transcripts Microsoft Word, } \\
\text { then Excel using double cycle } \\
\text { magnitude coding }\end{array}$ & $\begin{array}{l}\text { Transcripts Microsoft Word, } \\
\text { then Excel using double } \\
\text { cycle magnitude coding }\end{array}$ \\
\hline Software in use & QRS NVivo R1 & QRS NVivo R1 & QRS NVivo R1 \\
\hline $\begin{array}{l}\text { Manner of treating } \\
\text { discrepant cases }\end{array}$ & & Use selective code repeatedly & $\begin{array}{l}\text { Subsume codes into broader } \\
\text { codes or categories }\end{array}$ \\
\hline
\end{tabular}


The following table summarizes gender participation in data collection versus tribes.

Table 3. Gender and Tribe Participation

\begin{tabular}{llllll}
\hline Number & Tribe/gender & Male & Female & Total & Province \\
\hline 1 & Kusu & 0 & 1 & 1 & Maniema \\
2 & Lokele & 1 & 1 & 2 & Tshopo \\
3 & Luba & 1 & 4 & 5 & Kasai Central/Oriental \\
4 & Lubakat & 1 & 0 & 1 & Tanganyika \\
5 & Manianga & 1 & 1 & 2 & Kongo Central \\
6 & Mbala & 0 & 2 & 2 & Kwilu \\
7 & Moboma & 1 & 0 & 1 & Mai-Ndombe \\
8 & Ndibu & 1 & 1 & 2 & Kongo Central \\
9 & Ngbandi & 1 & 1 & 2 & Sud-Ubangi \\
10 & Ngoli & 0 & 1 & 1 & Kwango \\
11 & Ntandu & 0 & 1 & 1 & Kongo Central \\
12 & Pende & 1 & 0 & 1 & Kwilu \\
13 & Sakata & 1 & 1 & 2 & Mai-Ndombe \\
14 & Sona & 0 & 2 & 2 & Kongo Central \\
15 & Songye & 1 & 0 & 1 & Eastern Kasai \\
16 & Suku & 0 & 1 & 1 & Nord Kivu \\
17 & Tetela & 2 & 0 & 2 & Sankuru \\
18 & Yaka & 2 & 3 & 5 & Kwango \\
19 & Yansi & 1 & 3 & 4 & Kwilu \\
20 & Yombe & 1 & 3 & 4 & Kongo Central \\
& Total & 16 & 26 & 42 & \\
\hline
\end{tabular}

Looking at the cultural diversity, several tribes were involved in this qualitative study. This would more likely have a positive impact on the results. This inquiry included at least 13 of the 26 major provinces in Congo-Kinshasa as described in Figure 2. Data collected show that not only was female participation about $61.9 \%$ higher but also Luba and Yaka tribes had the highest participation with $11.9 \%$ each, followed by Yansi and Yombe tribes with $9.52 \%$ of participation each. There were more Luba women than others in this study for $9.52 \%$ in terms of participation.

Because of the need to arrange data in a systematic order with the purpose of synthesizing closer answers provided by respondents, the last version of NVivo R1 was used, and all data were coded from In-depth interviews, focus groups, and key-informant person interviews. Qualitative data were entered by file as follows: focus group English BDD, focus group English men Kin, focus group English women Kin, Henry Muk Key informant English, In-depth interview English IG, In-depth interview English KR, In-depth interview MR, In-depth interview English NP, In-depth interview SA, In-depth interview English BDD MG, In-depth interview English BDD NYA, In-depth interview English PNM, In-depth interview English BDD RN, and Raymond Kel Key Informant English. Then cases entered in NVivo were coded using multiple patterns. The first one was 'cultural meanings' with components such as: condom rejection for cultural reasons, female genital mutilation, Kintwidi phenomenon, levirate marriage, sexual cleansing, sororate marriage, stigma and discrimination, and unprotected receptive vaginal or anal intercourse.

\section{Results}

This qualitative study involved a total of 42 respondents as follows: two men as key-informant persons, 12 female and six male participants questioned separately in a focus group, five in-depth interviews, and 13 PLHIVs in a focus group for Kinshasa. Additionally, Bandundu-city offered a data collection of four in-depth interviews with one male and three female PLHIVs. The following table depicts demographics of all participants in this study. 
Throughout this research, several questions were asked to respondents in order to meet my goal. After the informed consent form signing process and their voluntary participation, they were asked three major questions below found. Because of the exclusion of the third city for bias prevention, Mbandaka did not have any interviews.

Table 4. Different Interviews by Setting Locations

\begin{tabular}{lllllll}
\hline \multirow{2}{*}{ Number } & \multicolumn{2}{l}{ Focus group } & \multicolumn{2}{l}{ In-depth interview } & \multicolumn{2}{l}{ Key-informant interview } \\
& Expected & Occurred & Expected & Occurred & Expected & Occurred \\
\hline Kinshasa & 3 & 2 & 6 & 5 & 1 & 1 \\
Bandundu & 3 & 1 & 6 & 4 & 1 & 1 \\
Mbandaka & 0 & 0 & 0 & 0 & 0 & 0 \\
Total & 6 & 3 & 12 & 9 & 2 & 2 \\
\hline
\end{tabular}

Cases entered in NVivo were coded using multiple patterns. The first one was 'cultural meanings' with eight random components such as: condom rejection for cultural reasons, female genital mutilation, Kintwidi phenomenon, levirate marriage, sexual cleansing, sororate marriage, stigma and discrimination, and unprotected receptive vaginal or anal intercourse.

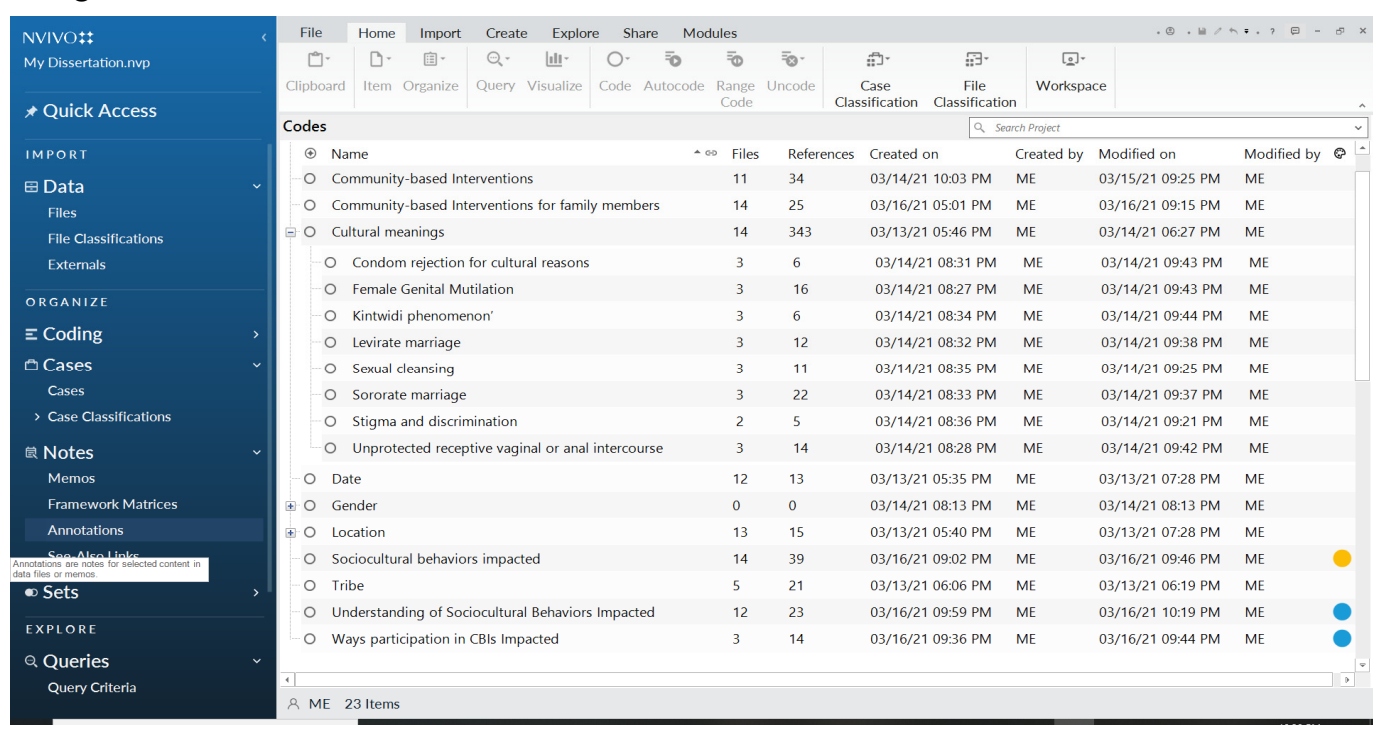

Figure 1. NVivo depiction of coding cultural meanings of traditional concepts

When observing social actions, every data collection must be performed with scrutiny, recording qualitative information either by quantitazing data collected, or coding alphanumerical data (Saldana, 2016, p. 26). If the table above depicts 8 components of cultural meanings ending with unprotected receptive vaginal or anal intercourse to illustrate a part of respondents' cultural meaning, the second code related to this NVivo R1 data recording was 'gender.' Gender coded as ' $F$ ' for female and ' $M$ ' for male, with this screenshot example given while organizing focus group in Bandundu-city data collection:

\subsection{In What Ways Has Participation in CBIs Impacted Sexual Behaviors Among Congolese PLWH and Their Community in General}

According to data collected, the majority of respondents suggested that CBIs consist of a package of holistic activities for PLWHs starting from the outreach to their social assistance. Some meaningful features of that approach are VCTs, HVs, and Income-Generating Activities (IGA). Those known iconic activities are the cornerstone of social actions designed to strengthen the medical aspects of the long walk through the HIV disease journey. For instance, one of the focus groups suggested that "CBIs have played an important role, mainly in how to have responsible sex by correctly using condoms. CBIs have helped us through counseling and practical advice, they also have contributed to access to medicines. CBIs allowed PLWHs to get married because in the past we thought PLWHs could never get married."

I also learned from this unique qualitative study that besides addressing stigma and discrimination, CBIs implemented during this decade helped PLWHs to really become responsible and take care of their family members beyond their own children. As community heroes, PLWHs became a living testimony of their previous 
sexual behaviors. Consequently, other community members could learn from their social situation and adopt a positive sexual attitude based on multiple socioeconomic consequences of HIV affecting working parents. PLWHs said for example, "we live positively with responsible sex, and we are able to give birth to HIV-free children." This is a high level of understanding not only their rights but also how it is possible for a PLWH to have a 'normal life' while being socially committed to societal norms. Because my trial timeframe with NVivo R1 expired, a small part of my data was explored using Microsoft Excel.

However, one of the interviewees suggested that "there is not so much big change but, I live like everyone else." This answer can be confusing, but the idea was as stated above that in a married couple of PLWHs, they can live a normal life. They can have unprotected sexual intercourse with his/her partner for reproductive purposes and give birth to an HIV-free baby if subsequent measures are taken. Surprisingly, one of them stated, "I became responsible for my life to live alone as I have not yet found a partner." This means that this individual is potentially changed and willing to stay in control of what he/she does sexually until he/she will find a partner to get married. The same respondent said, "condom is important for not getting contaminated by sexually transmitted diseases." This interviewee clearly seems to attribute a protective effect against HIV/AIDS to the correct condom use any time you have sex with unknown partners.

Another respondent said, "I have changed the way I have sex while sharing experience." At the same time, he/she stated regarding unprotected receptive sexual intercourse, "It is very risky that we can become the freeway of infections such as HIV/AIDS and STIs." Conversely, on condom rejection for cultural reasons, he/she suggested that without using a condom, "he is exposed to HIV and STIs without knowing it. If he has someone he can trust, there is no danger." This twisted idea of trusting someone without knowing his/her serological HIV status is an issue in regard to the expected results after 10 years of being in CBIs. Rather than following the same avenue, another person suggested, "I completely changed the way I was understanding sex without a condom, and I would never accept to have any intercourse without a condom. I became responsible and faithful."

\subsection{What Is the Meaning of Community-Based Interventions for Family Members}

The findings of the second research question can be viewed as externalities of CBIs. This means grasping PLWH's understanding of CBIs and their multifaceted consequences of a decade of interventions among their communities in DR Congo. For instance, one of the respondents said, "my family was happy with these interventions because it helped me to live in peace and to engage in small business in order to send my children to school." Because of CBIs, this person was able to come back to normal life, fight for survival and educate her children as school is not free in DRC. That made her a proud person in her family, because being a part of an impactful program.

However, some of them have a bad experience of CBIs, especially in regard to the way family members had been labeling them. For this interviewee, "community-based interventions were for my family members as a teasing response to me despite the improvement in my health." This answer reminds stigma and discrimination when looking at a person in a different way just because he/she is HIV infected or a beneficiary of any assistance because of the social status. This leads to the way a PLWH implements a response to changes. One of them thinks that "it is important to respond, "to any changes with solidarity, and courage regarding HIV-positive people." Family members can be a discouraging factor if they do not support your fight.

In summary, the meaning of CBI was remarkably diverse. For example, one patient said, “ $\ldots$ these interventions have strengthened my life and relationships with my family members." It seems to be clearly showing that there is a strong bond between that sick person and his/her family members due to the support brought with CBIs. Following in the same direction, another patient stated that he got "a real relief because, with my own strength, I could not get out of it." This PLWH suggested, "my family was happy with these interventions, such as with the counseling, home visits, foods, medications because it helped me live well and longer."

\subsection{What Are the Detailed Sociocultural Behaviors Impacted at the End of the Project}

Throughout this qualitative study, I learned that sociocultural behaviors may have changed due to a decade of project implementation. This could be valid at least in terms of daily practice and skills. At the same time, PLWH seems to be stating what they do in their lives around family members. Talking about sexual intercourse, this PLWH in Bandundu stated, "I safely use all the skills I received from my counseling, and I stopped cheating." Due to CBI implementation, it is understood here that the person had changed his/her sexual behavior at the end of this project.

Because of the relationship between HIV in Africa and sexual behavior, one of them suggested that "I changed my sexual behavior. I became reliable on only someone and began even counseling others how to protect themselves from HIV/AIDS." For this PLWH, "my sexual life was strengthened, and I became very faithful to my wife." This 
seems to be the main behavior said impacted by the project. Another PLWH thought that "all activities carried out under the project have led to a significant change in socio-cultural behavior, such as outreach, screening, etc." This PLWH stated, "this became an opportunity to speak out without shame or fear. It changed our sexual behaviors and prevented us from having several sexual partners. We became faithful, we knew how to use the condom correctly and regularly. This prevented us from unprotected intercourses."

From a diverse opinion, most PLWHs took the decision of living positively by accepting their HIV + status. They adopted a culture of protecting themselves and other measures targeting law enforcement. They learned the culture of living in society despite their HIV status, and they understood how dangerous it is to have sex with anyone with no condom. This must be done because they need to protect themselves. One of the most important deliverables in this project was the resilience in solving their problems. This concept of resilience means here the ability to cope with their local situation.

\section{Discussion}

From December 2020 to February 2021, all qualitative data gathered were reduced, synthesized, analyzed and results were kept in an authorized fashion. The tables below built contain data explaining how Congolese PLWHs understand the influence of CBIs on their behaviors since the implementation of this program has started/ended. In each table/graph, information gathered illustrates outcomes of three focus groups, two key-informant person interviews and nine in-depth interviews performed in Kinshasa and Bandundu-city. The following graphs will provide detailed data collected after reduction.

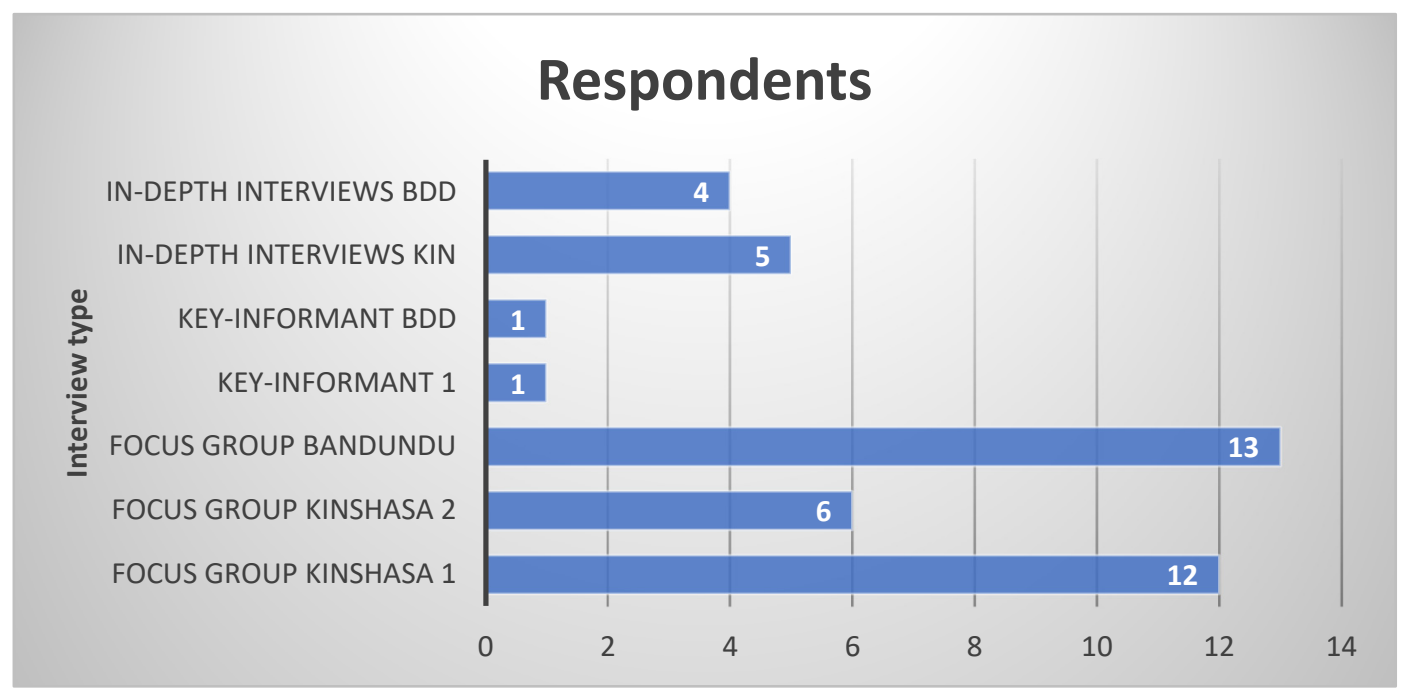

Figure 2. Interview Types and Number of Participants

Most people were interviewed in focus groups from the female group built-in Kinshasa, and from the focus groups in Bandundu-city. With 55 negative answers on cultural meanings, the message sent is meant to explain the disagreement of PLWHs with several practices. Some of them are taken as positive arguments and support those cultural practices. For instance, when talking about stigma in Suku tribe, it is considered as a rejection by casting a bad look from someone. For Manianga people, it is a way of living differently from other community members. The Luba tribe thinks that stigma is a way to denigrate someone, lessen his community value. All these assessments are taken as a negative value in society. 


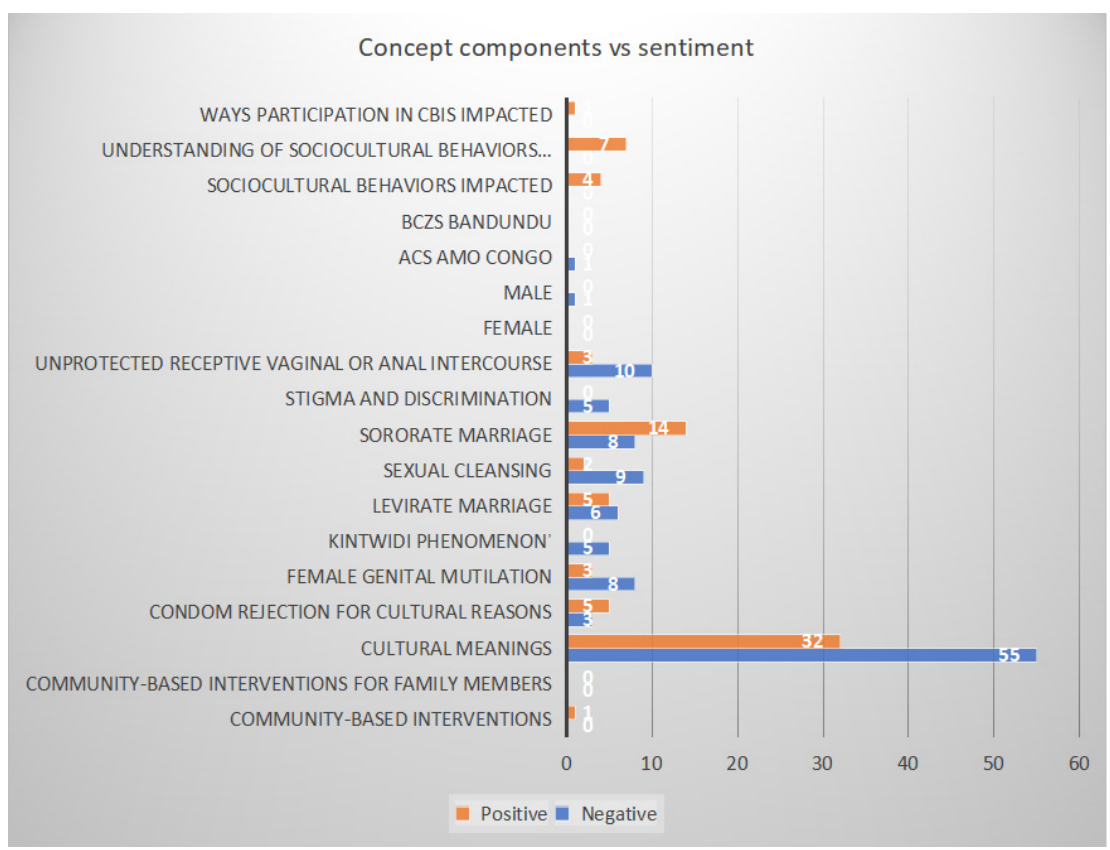

Figure 3. Key-Informant person Kinshasa

This graph shows that negative opinions from Congolese PLWHs are far way larger than positive opinions regarding several practices in the community. For example, when talking about the Kintwidi phenomenon, he stated, "... this can be a risky behavior on not knowing their HIV status can lead to STI infection and HIV/AIDS; cause suicides and deaths when you don't agree with the old partner you are offered; you can also be stressed out for a marriage without consent." He also said on the sororate marriage that, "the positive side of it is the decreasing of the orphan concept in the community or as a family."

KR's interview was one of the richest data collected during this ethnographic research. It provided the SEM backbone information regarding the influence of CBIs at each level. According to this interviewee, CBIs have impacted her life at different layers of her life. At the personal level, she recovered the social consideration that she previously lost, at the family level, no one thinks of her death anytime soon, at the community level, self-support group friends continue to hang out with her, at the organizational level, she manages to be independent, and at the law level, she knows her rights and her duties.

Data collected from MR interviewee indicated that the individual lives straightforward with her family and her community in terms of behaviors. She came out hiding and was back to normal life with strong contact with her community. This is a significant change for that person because in her language they say, "Udi mupeta budi penshi ewu" meaning, whoever caught a deadly disease is locked in the house. The SA figure interview illustrates from the Tetela tribe regarding the Kintwidi phenomenon that the marriage between an uncle and a niece has value in their culture because it is done to enhance the spirits of their ancestors. HIV/AIDS is known as "emoka soni", meaning an ashaming disease. However, in order to keep the spirit of the family among them, people should wisely prevent members from contracting HIV in traditional forced marriage.

In this case, the interviewee (NP) explains several concepts and seems to disagree with them. For instance, she stated that Sexual Gender-Based Violence (SGBV) is known in her culture as "BANUANGATA KUBUKOLE", which means having sex with a woman by force and do whatever you want. In other words, a woman is considered as a simple thing using the expression "TSHINTU". Talking FGM and SGBV, MD respondent stated, "FGM can be the cause of infections such as HIV, especially if the materials used are not quite sterilized. And SGBV can also be the gateway to STIs like HIV because it is done by forcing a woman." She summarized that, "it is important to sterilize the materials but also to avoid any act of violence such as taking the woman by force."

According to NYA BDD respondent, he was not using condoms in the past, because he thought that condoms can cause abdominal pain to a lady and other illnesses. In their culture, HIV/AIDS was known as the "kimbefo ya lufwa", meaning an incurable disease or a disease leading to death. The milestone with this interviewee is that CBIs have helped him understand the role of a condom and he is always correctly using it now. PNM respondent from Bandundu stated that receptive vaginal intercourse is done unprotected when they trust their partners and especially for pleasure reasons. According to their culture, sexual intercourse performed by the anus is a risk factor 
for STIs. For them, people do not use the condom because of they think it causes pain, also they say they do not feel any pleasure when bearing it. They said that it is necessary to do it rather as "nitu na nitu" etymologically meaning, 'body to body' or without any barrier to make sure they feel the sexual pleasure. Fortunately, CBIs have changed his behaviors, now he can put on a balance the weight-interest between pleasure and his own life. He stopped cheating not only to protect his sexual partner but also himself.

RN sustains that she changed her personal behavior on using condoms as she responded. However, she stated that her family members did not want to eat food provided by ACS AMO Congo pretending to prevent themselves from contracting HIV (mindset bias). From a worthless or a thief in my family, I became worthy and started serving most of them as an example of addressing HIV issues. She stated, "I changed my sexual behavior. I became reliable on only someone and began even counseling others how to protect themselves from HIV/AIDS." The respondent did not find many advantages in the cleansing phenomenon. According to her, their population needs to be mobilized regarding HIV prevention because FGM and SGBV drive to STIs, therefore they must be discouraged in their community.

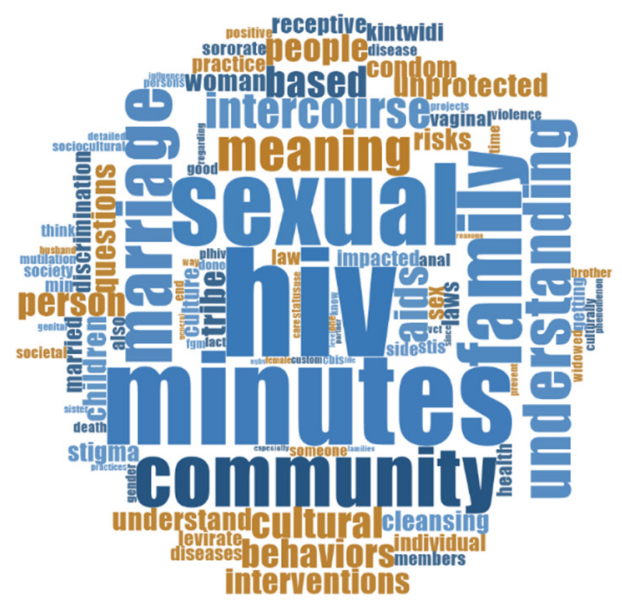

Figure 4. The NVivo R1 Word Cloud from Data Collected

After assessing the whole data collection, this word cloud from NVivo R1 represents the most frequent words used during the study. Overall, amongst the concepts employed 'HIV' is the main word utilized, followed by 'sexual,' then 'family,' 'community,' and 'marriage,' etc. It can be clearly stated that their understanding and meaning have a significant position before intercourse, cultural behaviors, and intervention.

\section{Conclusion}

The theoretical framework of this ethnographic study was the SEM (Glanz et al., 2015). Based on the cultural understanding of eight random key concepts, 42 interviewees responded to a questionnaire using three technics related to qualitative research: (1) focus groups, (2) in-depth interviews, and (3) key-informant interviews. Self-assessment was the fundamental approach used to understand whether behaviors of PLWHs involved in CBIs for at least a decade were positively or negatively influenced by the program designed to set them socially and financially independent in their communities. Because the SEM of health behavior posits five core principles cited in this study, findings of the current study need to be interpreted according to these principles (Glanz et al., 2015) as acknowledged in the theoretical/conceptual framework.

There are several levels of influence on health behaviors (Glanz et al., 2015). At first, the focus group in Bandundu reported that VCT and home visits provided abundant information regarding the correct use of condoms and responsible sexuality. They think PLWHs in Bandundu-city became proactive in providing preventive information to their peers. When PLHIVs learned about ART and the vertical transmission prevention method, they requested the right to get married and give birth to HIV-free babies. Two targeted levels by CBIs were sexuality with condom use at the individual level and general health through medication.

A second significant determinant of health behaviors is the environmental context in which they occur (Glanz et al., 2015). According to the focus group in Bandundu, Kintwidi phenomenon is a cultural behavior found in the Yansi tribe in Greater Bandundu. Providing information related to risky sexual behaviors in that community was the foundation of the approach among PLWHs undergoing CBIs in Bandundu-city. The same approach might not provide similar results elsewhere because of different environmental contexts. In this study, HIV/AIDS interviewees were able to describe potential risks of the disease because this type of traditional marriage depends on each family tradition. 
Third, as noticed, behavioral changes occur with interactions across different levels (Glanz et al., 2015, p. 48). According to the focus group of men performed in Kinshasa, because their community went through some negative influence occurring from FGM (community level), individuals were able to decline any culturally designed FGM offers in opposition with new Congolese laws designed. New laws were meant to promote health adolescents through a specific program (Programme National de la Santé de adolescent) in healthy communities. That group explained how urban Luba PLWHs and their community members refused to let girls be sexually mutilated for men's pleasure.

Fourth, when looking for real social change, the ecological model always targets a specific behavior (Glanz et al., 2015, p. 49). Because of the poverty, most PLWHs contracted the disease either when cheating on their spouse, or through unprotected sexual intercourse via prostitution. CBIs provided PLWHs with IGAs and home visits for follow-up. Most of them stopped engaging in prostitution with the income they were making. They started sending children again to school and never came back to that negative sexual behavior. As they have positively changed behaviors, people who were refusing to take their daily medications in the past became peer mentors for new PLWHs in Bandundu-city and ACS AMO Congo Kinshasa with community volunteers.

Fifth, because of their multiplicity in levels of interventions, this approach is set to be the most effective in behavioral changes in the community (Glanz et al., 2015, p. 49). Most PLWHs in Kinshasa learned new jobs according to their choice. School fees were paid off for children, IGAs were given to parents, home visits were performed to make sure they have been complying with their daily medication around family members, community groups have been created, UCOP+ was the major local organization including all PLWHs, and contacts were established for regular follow-ups regarding laws protecting them.

In summary, this self-assessment targeting the multifaceted intervention provided by a decade of CBIs among PLWHs in Congo starting in 2004 seemed to positively influence lives of a group of individuals. They were able to accept their status as PLWHs and willingly share information. The focus group of women in Kinshasa explain their resiliency and suggests that PLWHs are accepted by their family members because they learned more about the disease. HIV/AIDS no longer implies a shorter lifespan. For instance, one respondent from in-depth interviews in Kinshasa stated:

(1) At the personal level, "I recovered the social consideration I lost before."

(2) At the family level, "no one thinks of my death anytime soon."

(3) At the community level, "self-support group friends continue to hang out with me."

(4) At the organizational level, "I manage not to be dependent."

(5) At the law level, "I know my rights and my duties." (KR Interview-Kinshasa)

\section{Availability of Data and Materials}

All data collected are available using different supports as follows:

(1) 42 French written hard copies of informed consents and filled interview forms containing respondent answers.

(2) Audiotaped interviews from three focus groups and several individual interviews are kept on a SONY recorder device ICD-BX140 in Tacoma, WA.

(3) English translated copies of all interviews kept on my personal computer.

(4) Detailed information in my accepted final dissertation.

\section{Limitations of the Study}

One of the important limitations of this study is the selection bias due to the fact that I am providing a study summary related to a self-assessment as a snapshot on PLWHs starting in 2004 (Aschengreau \& Seage, 2014). Also, because of the high mortality of HIV in Africa, large numbers of patients are dead, and multiple others did not attend the interview sites due to the COVID-19 pandemic. Also, the sample taken for this qualitative study cannot be stated to be representative of all the Congolese population. However, the snowball sampling selection could potentially decrease the chance of having strong speakers for high-quality performance (selection bias). Also, due to the fact that information provided is from the past, there is a risk of recall bias in individual interviews. That is why triangulation and repetitive questioning were used in focus groups and all data collection approaches to obtain the best answers possible from each question.

This qualitative study does not have a previous baseline research comparison, as a database ready to be used as a gold standard study. Indeed, finding an existing primary study would have served as a comparison inquiry to better 
grasp the potential influence of CBIs among PLWHs in Congo. Also, the easiest way to measure the impact of CBIs in terms of health should be the HIV testing process. Unfortunately, relevant approaches to evaluate the impact of specific interventions in qualitative studies are made of complex components, including a gold standard of information from the same or a similar community. That referential loop does not exist in the central African region in terms of cultural behaviors, creating a need for field innovation. Finally, a real experimental design can be suggested to attribute behavioral change to CBIs.

That is partly why I requested the second IRB approval from the KSPH, after sharing information with the Walden IRB. The remote data collection was authorized in December 2020, and I trained the research assistant, before having pre-organizational meetings and field visits prior to each local interview. Useful forms and documents were printed out, respondents were selected and invited at the site for the interview. The informed consent form was read to each of them, letting them know that participation was voluntary, and they were free to leave the study anytime they wanted without any constraints. They signed two informed consent forms, keeping a copy for each of them and interviews occurred in confidentiality with a lunch provided, and a \$10-transportation card.

At the end, data collected were kept confidential and outcomes were shared with the KSPH. However, because of the difference in languages, data were collected in Lingala, then translated in French, before requesting the second English translation. This may potentially generate confirmation biases due to personal interpretations of information collected from respondents. Also, the lack of comparison studies would not help to reduce any potential gaps in the influence of CBIs as self-assessment is naturally subjective. Finally, for example, conclusions were drawn from Bandundu-city regarding the Kintwidi phenomenon would never be generalizable in the whole country, except for the Yansi and Luba people wherever they locate in DR Congo.

\section{Abbreviations}

ACS AMO Congo: Action Communautaire Sida - Avenir Meilleur pour les Orphelins au Congo

AIDS: Acquired immunodeficiency syndrome

ART: Antiretroviral treatment

CAQDAS: computer-assisted qualitative data analysis software

CDC: Centers for Disease Control and Prevention

CBIs: Community-based interventions

DFID: Department for International Development

DRC: Democratic Republic of Congo

FGM: female genital mutilation

HIV: Human immunodeficiency virus

HVs: Home visits

IGAs: Income generating activities

IRB: Institutional review board

KSPH: Kinshasa School of Public Health

MSM: men who have sex with men

PEPFAR: U.S. President's Emergency Plan for AIDS Relief

PLHIV: person/people living with HIV

PNLS: Programme National de Lutte contre le Sida (HIV/AIDS national programme)

SEM: Socioecological model

SGBV: sexual gender-based violence

STD/I: Sexually transmitted diseases/infections

UNAIDS: United Nations' AIDS

UNICEF: United Nations International Children's Fund

VCT: Voluntary Counseling and Testing

WHO: World Health Organization 


\section{Conflicts of Interest}

There are no conflicts of interest from this article, because this study was authorized by the Walden University IRB and supervised by the Kinshasa School of Public Health.

\section{Ethical Standards}

One of the major responsibilities of any researcher is to act always in an ethical manner when working (Rudestam \& Newton, 2015). Social research is a naturally person-centered approach meant to understand and explain different phenomena occurring around the world, so the authenticity of the relationships between researchers and respondents is fundamental (Ravitch \& Carl, 2017). Conducting research on human beings is delicate and requires high standard ethics usually managed at universities by the Institutional Review Board (IRB) (Babbie, 2015). University IRBs formalize research ethics and institutionalize procedures to guaranty that the informed consent of the participant is freely obtained prior to entering any research project (Rudestam \& Newton, 2015; Salazar et al., 2015). Therefore, the IRB agreement must be obtained prior to any field contact with respondents, based on potential ethical issues linked to HIV worldwide and the current COVID-19 pandemic.

After the Walden IRB approval, the Congolese Committee of Ethics (CCE) from the Kinshasa School of Public Health (KSPH) was contacted with the Walden approval document in order to proceed with data collection under the agreement of the Congolese Research and Health Ministries as required by the law in DRC. These agreements guided all contacts with the National Program addressing HIV/AIDS (PNLS) and participants. The treatment of human participants in this study strictly responded to the following principles: (1) voluntary participation using the golden rule of informed consent, (2) no harm to the participants, (3) anonymity and confidentiality (Babbie, 2015). So, after explaining the whole process to the IRB and each respondent, I obtained: (1) the IRB approval, (2) a CCE permission with local supervision, (3) the individual informed consent letter before starting data collection.

The recruitment was done using PNLS Bandundu and other institution registers (General Referral Hospital of Bandundu and ACS AMO Congo) with the research assistant under the supervision of KSPH, but snowball sampling was used for the homogeneity and fluidity in communication between peers. The initial group of selected respondents received a briefing related to the confidentiality and the anonymous character of data collection (Babbie, 2015). The main elements of the informed consent were based on time commitment, benefits to be expected, potential risks and how to handle them, explained the voluntary participation in the study, advised the participants of payment, explained the limits of confidentiality, and informed them about the debriefing (Rodestam $\&$ Newton, 2015). The use of audiotape (PLWHs and siblings) and audio taping (key informant) was explained to the participants. Self-withdrawal would have occurred anytime, same as allowing questions before, during, and after data collection. At the end of the process, a permanent confidential plan of communication with participants was ensured whenever they wanted.

\section{References}

Afriyie, J., \& Essilfrie, M. E. (2019). Association between risky sexual behavior and HIV risk perception among in-school adolescent in a municipality of Ghana. Ghana Med. J., 53(1), 29-36. https://doi.org/10.4314/gmj.v51i1.5

Ahmed, S. I., Farooqui, M., Syed Soulaiman, S. A., Hassali, M. A., \& Lee, C. K. C. (2019). Facilitators and barriers affecting adherence among people living with HIV/AIDS: A qualitative perspective. J. Patient Exp., 6(1), 33-40. https://doi.org/10.1177/2374373518770805

American Psychological Association. (2020). Publication manual of the American Psychological Association (7th ed.). https://doi.org/10.1037/0000165-000

Aschengrau, A., \& Seage III, G. R. (2014). Essentials of epidemiology in public health (3rd ed.). Jones \& Bartlett Learning.

Babbie, E. (2015). The basics of social research (7th ed.). Cengage Learning.

Belmar, J., \& Stuardo, V. (2017). Antiretroviral adherence treatment for HIV/AIDS in women: A sociocultural perspective. Rev. Chilena Infectol, 34(4), 352-358. https://doi.org/10.4067/s0716-10182017000400352.

Bhatta, D. N., Liabsuetrakul, T., \& McNeil, E. B. (2017). Social and behavioral interventions for improving quality of life of HIV infected people receiving antiretroviral therapy: A systematic review and metanalysis. Health Qual. Life Outcomes, 15, 80. https://doi.org/10.1186/s12955-017-0662-4

Burman. C. J., \& Aphane, M. (2017). Complex HIV/AIDS landscapes: Reflections on how 'path creation' influenced an action-oriented intervention. Syst Pact Action Res, 30, 45-66. https://doi.org/10.1007/s11213-016-9385-4 
Centers for Disease Control and Prevention. (2016). The scope and impact of HIV in the United States. Retrieved from https://www.cdc.gov/nchhstp/newsroom/docs/factsheets/todaysepidemic-508.pdf

Centers for Disease Control and Prevention. (2017). Democratic Republic of Congo: Country profile. https://www.cdc.gov/globalhivtb/where-we-work/drc/drc.htlm

Collins, \& Sapiano. (2016). Lessons learned from dissemination of evidence-based interventions for HIV prevention. American Journal of Preventive Medicine, 4(2), S140-S147. https://doi.org/10.1016/j.amepre.2016.05.017

Conroy, A. A. et al. (2019). Food insecurity and violence on a prospective cohort of women at risk for or living with HIV in the U.S. PloS One, 14(3), e0213365. https://doi.org/10.1371/journal.pone.0213365

Creswell, J. W., \& Creswell, J. D. (2018). Research design: Qualitative, quantitative, and mixed method approaches. Thousand Oaks, CA: Sage Publications.

Dao, L. U. et al. (2019). Risk and resilience: The syndemic nature of HIV/AIDS in the indigenous highland communities of Ecuador. Public Health, 176, 36-42. https://doi.org/10.1016/j.puhe.2019.02.021

Davis, R., Campbell, R., Hildon, Z., Hobbs, L., \& Michie, S. (2015). Theories of behaviours and behaviour change across the social and behavioral sciences: A scoping review. Health Psy. Rev., 9(3), 323-344. https://doi.org/10.1080/17437199.2014.941722

Fawole, O. I., Balogun, O. D., \& Olaleye, O. (2018). Experience of gender-based violence to students in public and private secondary schools in Ilorin, Nigeria. Ghana Med J., 52(2), 66-73. https://doi.org/10.4314/gmj.v52i2.1

Fearon, E., Wigging, R. D., Pettifor, A. E., \& Heargraves, J. R. (2015). In the sexual behaviour of young people in sub-Saharan Africa influenced by their peers. A systematic review. Soc. Sciences \& Med., 146(2015), 62-74. https://doi.org/10.1016/j.socscimed.2015.09.039

Gilbert, J. A. et al. (2015). Integrating community-based interventions to reverse the convergent TB/HIV epidemics in rural South Africa. PlosOne. https://doi.org/10.1371/journal.pone.0126267

Glanz, K., Rimer, B. K., \& Viswanath, K. (2015). Health behavior: Theory, research, and practice (5th ed.). San Francisco, CA: Jossey-Bass.

Gorofalo, R., Kuhns, L. M., Reisner, S. I., Biello, K., \& Mimiaga, M. J. (2018). Efficacy of an empowerment-based, group delivery HIV prevention intervention for young transgender women: The project Life Skills randomized clinical trial. JAMA Pediatr., 172(10), 916-923. https://doi.org/10.1001/jamapediatrics.2018.1799

Hickson, D. A. et al. (2015). Rationale, design, and methods of the Ecological study of sexual behaviors and HIV/STI among American men who have sex with men in the Southeastern United States (The MARI study). PloS One, 10(12), e0143823. https://doi.org/10.1371/journal.pone.0143823

Hile, S. J., Feldman, M. B., Raker, A. R., \& Irvine, M. K. (2018). Identifying key elements to inform the development of an HIV health behavior maintenance intervention. Am. J. Health Promot., 32(1), 48-58. https://doi.org/10.1177/0890117116669108

Jingwen Zhang, Cederbaum, Julie A., Jemmott, John B., \& Jemmott, Loretta Sweet. (2018). Theory-Based Behavioral intervention increases mother-son communication about sexual risk reduction among inner-city African Americans. Journal of Health Adolescents, 63(2018), 497-502. https://doi.org/10.1016/j.jadohealth.2018.04.017

Kaiser Family Foundation. (2019). The global HIV/AIDS epidemic. Retrieved from https://www.kff.org/global-health-policy/fact-sheet/the-global-hivaids-epidemic/

Leddy, A. M. et al. (2018). Food insecurity associated with inflammation in US women with HIV. J. Infect. Dis., 219(2), 429-436. https://doi.org/10.1093/infdis/jiy511

Luo, L., Cao, L., Hu, R., Xu, J., \& Wang, R. (2018). Status and associated factors of rush poppers use among newly diagnosed HIV-positive men who have sex with men in Wuhan, 2016. Zhonghua Yu Fang Yi Xue Za $\mathrm{Hi}, 52(12), 1287-1289$.

MacLean, J. R., \& Wetherall, K. (2021). The association between HIV-stigma and depressive symptoms among people living with HIV/AIDS: A systematic review of studies conducted in South Africa. Journal of Affective Desorders, 287, 125-137. https://doi.org/10.1016/j.jad.2021.03.027 
Malungu, J. R. (2001). Sexual cleansing (Kusalazya) and levirate marriage (Kunjilila mung'anda) in the era of AIDS: Changes in perceptions and practices in Zambia. Soc Sci Med., 53(3), 371-382. https://doi.org/10.1016/S0277-9536(00)00342-7

Mandumbu, R., \& Mariga, I. K. (2017). Improving agricultural technologies in HIV/AIDS infected/affected communities and for elderly farmers: The case of sub-Saharan Africa. World Development Perspectives, 6(2017), 38-44. https://doi.org/10.1016/j.wdp.2017.05.002

Martinez, O. et al. (2016). Integration of social, cultural, and biomedical strategies into an existing couple-based behavioral HIV/STI prevention intervention: Voice of Latino male couples. Plos One, 11(3), e0152361. https://doi.org/10.1371/journal.pone.0152361

Mataboge, M. L. S., Beukes, S., \& Nolte, A. G. W. (2016). The experience of clients and healthcare providers regarding the provision of reproductive health services including the prevention of HIV and AIDS in an informal settlement in Tshwane. Health SA Gesondheid, 21(2016), 67-76. https://doi.org/10.1016/j.hsag.2015.05.002

Mavhu, W., Willis, M., Mafuka, J., Mangenah, C., Mvuvudu, K., Bernays, S., Mangezi, W., Apollo, T., Araya, R., Weiss, H. A., \& Cowan, F. M. (2017). Evaluating a multi-component, community-based program to improve adherence and retention in care among adolescents living with HIV in Zimbabwe: Study protocol for a cluster randomized controlled trial. BMC, 18(478). https://doi.org/10.1186/s13063-017-2198-7

Merlin, J. S. et al. (2018). Intervention mapping to develop a Social Cognitive Theory-based intervention for chronic pain tailored to individuals with HIV. Contemp. Clin. Trial s Communic., 10(208), 9-16. https://doi.org/10.1016/j.conctc.2018.02.004

Mustafa, N. (2018). Cost-effectiveness-analysis: Education interventions that reduce the incidence of HIV/AIDS infection in Kenyan teenagers. International Journal of Educational Dev., 62(2018), 264-269. https://doi.org/10.1016/j.ijedudev.2018.06.001

Omori, R., \& Abu-Raddad, L. (2016). Population sexual behavior and HIV prevalence in in sub-Saharan Africa: Missing links? Int. J. Inf. Disease, 44(2016), 1-3. https://doi.org/10.1016/j.ijid.2016.01.005

Orisameri, T. C. (2016). Gender, Sexual Health Seeking Behavior, and HIV/AIDS among Tarok Women in North-Central Nigeria. Health Care Women Int., 37(6), 687-704. https://doi.org/10.1080/07399332.2014.971953

Ousley, J., Nesbitt, R., Kyaw, N. T. T., Bermudez, E., Soe, K. P., Anicete, R., Mon, P. E., Ei, W. L. S. S., Christofani, S., Fernandez, M., \& Ciglenecki, E. (2018). Increased hepatitis C virus co-infection and injection drug use in HIV-infected fishermen in Myanmar. BMI Infectious Diseases, 18. https://doi.org/10.1186/s12879-018-3558-y

Poku, N. K., \& Bonnel, R. (2016). Funding of community-based interventions for HIV prevention. Afr. J. AIDS Res., 15(2), 163-71. https://doi.org/10.2989/16085906.2016.1194300

Pretorius, J. B., Minrie, G., Freeks, F. E., \& Kruger, A. (2016). An HIV stigma reduction intervention for people living with HIV and their families. Health SA Gesondheid, 21(2016), 187-195. https://doi.org/10.1016/j.hsag.2015.11.005

Ravitch, S. M., \& Carl, N. M. (2016). Qualitative research Qualitative research: Bridging the conceptual theoretical and methodological. Thousand Oaks, CA: Sage Publications.

Rosenberg, M. S. et al. (2017). Sexual behaviors and HIV status: A population-based study among older adults in rural South Africa. J. Acquir. Immune Defic. Syndr., 74(1), e9-e17. https://doi.org/10.1097/QAI.0000000000001173

Rudestam, K. E., \& Newton, R. R. (2015). Surviving your dissertation: A comprehensive guide to content and process (4th ed.). Thousand Oaks, CA: Sage Publications.

Salazar, L. F., DiClemente, R. A., \& Crosby, R. J. (2015). Research methods in health promotion. San Francisco, CA: Jossey-Bass.

Saldana, J. (2016). The coding manual for qualitative researchers. Thousand Oaks, CA: Sage Publications.

Shan, W., \& Cui, G. (2018). La fatalité du phénomène Kintwidi au Congo-Kinshasa. Le Quotidien du Peuple. Retrieved from https://french.peopledaily.com.cn/VieSociale/n3/2018/0108/c31360-9312956.html 
Sharma, V., Tun, W., Sarna, A., Saraswati, L. R., Pham, M. D., Thior, I., \& Lutchers, S. (2018). Prevalence and determinants of unprotected sex in intimate partnerships of men who inject drugs: Findings from a prospective intervention study. International Journal of STD \& AIDS, 30(4), 386-395. https://doi.org/10.1177/0956462418802142

Shi, L., \& Johnson, J. A. (2013). Novick \& Morrow's, public health administration: Principles for Population-based management (3rd ed.). Burlington, MA: Jones \& Bartlett Learning.

Techasrivichien, T. et al. (2016). Changes in sexual behavior and attitudes across generations and gender among population-based probability sample from an urbanizing province in Thailand. Arch. Sex. Behav., 45, 367-382. https://doi.org/10.1007/s10508-014-0429-5

The World Bank Group. (2018). Congo Democratic Republic: population, total. Retrieved from https://data.worldbank.org/

U.S. President's Emergency Program for AIDS Relief [PEPFAR]. (2017). Democratic Republic of Congo: Country operation plan (COP)-Strategic direction plan. Retrieved from https://www.pepfar.gov/document/organization/266402.pdf

United Nations Programme on HIV/AIDS. (2018). UNAIDS data 2017. Geneva, Switzerland. Retrieved from https://www.unaids.org/sites/default/files/media_asset/2017_data-book_en.pdf

United Nations Programme on HIV/AIDS. (2018). UNAIDS data 2018. Retrieved from https://www.unaids.org/sites/default/files/media_asset/unaids-data-2018_en_pdf

Vera Cruz, G., Mateus, A., \& Dlamini, P. S. (2018). HIV prevention: Mapping Mozambican people's views on the acceptability of the widow's sexual cleansing ritual called pita-kufa. BMC Int Health Hum Rights, 18(1), 37. https://doi.org/10.1186/s12914-018-0177-z

Wekesa, E., \& Coast, E. (2015). Contraceptive need and use among individuals with HIV/AIDS living in slums of Nairobi, Kenya. Int. Journ. of Gyneco \& Obstetrics, 130(2015), 31-36. https://doi.org/10.1016/j.ijgo.2015.05.001

Westreich, E. (2004). Levirate marriage in the state of Israel: Ethnic encounter and challenge of a Jewish state. Israel Law Review, 37(2/3), 426-499. https://doi.org/10.1017/S0021223700012528

Whittle, H. J. et al. (2019). Food insecurity is associated with anxiety, stress, and symptoms of posttraumatic stress disorder in a cohort in cohort of women with or at risk of HIV in the United States. The Journal of Nutrition, 149(8), 1393-1403. https://doi.org/10.1093/jn/nxz093

World Health Organization. (2017). HIV/AIDS: key facts. Retrieved from https://www.afro.who.int/health-topics/hivaids

World Health Organization. (2018). HIV/AIDS. Retrieved from https://www.who.int/news-room/fact-sheets/detail/hiv-aids

World Health Organization. (2019). Global health observatory data. Retrieved from https://who.int/gho/hiv/en/

World Health Organization. (2019). Health risks of female genital mutilation (FGM). Retrieved from https://www.who.int/reproductivehealth/topics/fgm/health_consequences_fgm/en/

World Health Organization. (2019). Number of deaths due to HIV/AIDS. Retrieved from https://www.who.int/gho/hiv/epidemic_status/death_text/en/

World Health Organization. (2019). Stigma and discrimination. Retrieved from https://www.euro.who.in/en/health-topics/noncommunicable-diseases/mental-health/priority-areas/stigma-a nd-discrimination

Zhou, C., Dong, W., Lu, D. D., Zhong, F. J., Jiang, T. F., Cheng, H., Wu, Z. Y., \& Rou, K. M. (2018). A prospective cohort study to explore retention rate and behavior change among medium-to-low-tier female sex workers in Yuanzhou district, Yichun city. Zhonghua Yu Fang Yi Xue Za Zhi, 52(12), 1295-1297.

\section{Copyrights}

Copyright for this article is retained by the author(s), with first publication rights granted to the journal.

This is an open-access article distributed under the terms and conditions of the Creative Commons Attribution license (http://creativecommons.org/licenses/by/4.0/). 